tradition in engineering education. First he seems to have invented the idea that a mechanical laboratory is an appropriate part of an American Enginecring School. It is, of course, difficult in 1939 to realize that in 1870 this idea had to be invented.

Thurston's conception of such a laboratory was a threefold one; first, it should be a place where a student could become practically acquainted with working machinery; secondly, it should be a place where staff and students, working together, might by research make important contributions to the progress of engineering; and thirdly, it should bo a place to which industry could bring its problems, whether of testing, of design and development, or of a still more fundamental nature.

For his laboratory Thurston invented testing machines, and as a servant of industry the laboratory played an important part when few, if any, industries had their own plant for routine testing. From "a schedule of charges" dated 1877, and signed by Thurston, it appears that a test on the "autographic recording testing machine, of strength, ductility, resilience, and determination of elastic limit, elasticity, homogeneousness of structure and amount of internal strain, with strain-diagram and record" sould be had for threo dollars. A trial of a steam engine or boiler could be made for twenty-five dollars plus sixty cents an hour for field and office labour.

Thurston also had a conception of the fundamental position in mechanical engineering of the two great fields of the study of the properties of materials and of the problems of power. Further, he foressw the position engineers were likely to occupy as industrial executives, and himself set an example to others by taking part in public affairs. Ho exemplified, concluded Dr. Davis, "a conception of the scopo of the service of the engineer that may well be our inspiration and ideal for many years to come".

The fourth address was by Dr. W. F. Durand, his biographer, who dealt with Thurston's eighteen years, 1885-1903, at Cornell, and the concluding address was by Prof. S. C. Hollister, dean of the College of Engineering, Cornell, and was entitled "Looking to the Future". After referring to the great material developments since 1868, when engineering was first taught at Cornell, Prof. Hollister asked, "What has all this development done to human living ?" New problems have arisen of vast social import, and to overy phase of the scene, as he saw it, the engineor has a direct relation. He must be prepared to cope successfully with changes wrought by scientific and technical advance; ho is concerned with production, processes and organizations; $h \theta$ is involved in problems of management, finance, public relations and government. It seems clear that he is bound to bo involved more and more in the social and economic problems that lie ahead.

There is but one way of preparing young men for our expanding technical future, namely, to train them broadly and deeply in the fundamental sciences. Some feel that engineers are not trained in civic consciousness and usefulness. Prof. Hollister thinks it only fair to say that the whole educational field awaits with interest convincing testimony that any given curriculum accomplishes this very desirablo end. Civic consciousness is a matter of community attitude rather than the result of studying any system of subjects. The surest way to provide the right community attitude is to prepare men and women thoroughly for the parts which they are to play in the community. Cornell for many years has, in varying degrees, been functioning in this direction.

\title{
MANUFACTURE OF RADIO SETS FOR EXPORT
}

\begin{abstract}
A CCORDING to the Electrical Times of Novem. A ber 16, British manufacturers are often criticized for not studying the requirements of overseas markets. The reason for much of this criticism is easy to understand, as the conditions in the home markets of several of our international competitors are very similar to those in overseas countries which are large purchasers. To take a case in point, consider the export of radio sots.

It is common knowledge that, in the early days of foreign competition in the radio market, foreign competitors took the lead. In the United States, for example, where a widespread short-wave broadcasting system was employed, manufacturers found that little modification to the standard models was required to make them suitable for reception to distant parts of the world. British manufacturers had no similar home experience to rely on. Several of the leading firms in Great Britain have now built up an ex. port market for models which have been specially designed for overseas use and have achieved success in winning back lost ground. The General Electric Co., Ltd., has an organization of a world-wide network of completely equipped and technically staffed branches which offer great facilities for before and after sales service. Its experts travel the world studying reception conditions and problems at firsthand. In one tour alone Nigeria and Siam, Canada,
\end{abstract}

India, Now Zealand and Hawaii were visited, the total distance traversed being 50,000 miles. As a result of the valuable information obtained great improve. ments in design were facilitated and many special tests, which every G.E.C. overseas radio receiver now undergoes as a matter of routine, were devised.

Illustrations are given in the Electrical Times of the apparatus used in the special laboratory and factory tests on the sets in the 'humidity cabinet'. In this cabinet any required temperature and relative humidity can be obtained and also the cyclic varia. tions representative of tropical climates. Synthetic resin insulation, used for wave change switches, and rubber insulation receive special treatment in respect of both electrical and mechanical properties. In the artificial ageing test, specimens are subjected to high temperatures in an oxygen atmosphere and must remain unimpaired after 200 hours' treatment. One of the tests for the mechanism of awitches is to perform satisfactorily 50,000 operations. A motor-driven reciprocating mechanism operates the switch during the test. An instrument is also used to check the moisture content of wooden components to ensure that seasoning has been thorough. During the manufacture of mica condensers all the operations are carried out in a filtered air-conditioned room and glass screens protect the condensers from the operator's breath. 